\title{
INCIDÊNCIA FÚNGICA NO ARROZ (ORYZA SATIVA) COMERCIALIZADO NO MUNICÍPIO DE SOURE - PARÁ
}

\section{ARTIGO ORIGINAL}

SILVA, Noemy Silva da ${ }^{1}$

JESUS, Jess Arthur Moura de ${ }^{2}$

BIANCALANA, Adriano ${ }^{3}$

PAMPLONA, Adriane da Silva ${ }^{4}$

BIANCALANA, Fernanda Simas Corrêa ${ }^{5}$

SILVA, Noemy Silva da. Et al. Incidência fúngica no arroz (Oryza sativa) Comercializado no Município de Soure - Pará. Revista Científica Multidisciplinar Núcleo do Conhecimento. Ano 05, Ed. 03, Vol. 10, pp. 109-132. Março de 2020. ISSN: 2448-0959, Link de acesso: https://www.nucleodoconhecimento.com.br/saude/incidencia-fungica-noarroz

\footnotetext{
${ }^{1}$ Graduanda pela Universidade Federal do Pará - UFPA.

${ }^{2}$ Graduando do $3^{\circ}$ semestre de Direito da Faculdade Estácio do Pará - FAP.

${ }^{3}$ Doutor em Biologia Celular e Estrutural pela Universidade Estadual de Campinas, Brasil (2009).

${ }^{4}$ Graduanda pela Universidade Federal do Pará - UFPA.

${ }^{5}$ Doutora em Ciências Médicas pela Universidade Estadual de Campinas, Brasil (2011). Mestre em Ciências Médicas pela Universidade Estadual de Campinas, Brasil (2007).
} 


\section{RESUMO}

O arroz (Oryza sativa) é um dos alimentos mais consumidos no mundo todo. Por isso, sua qualidade e sanidade são de extrema importância, pois qualquer contaminação poderá afetar a saúde do consumidor e, por ser um cereal que serve como excelente substrato, os fungos encontram condições adequadas para se desenvolverem. Com isso, o objetivo desta pesquisa é avaliar a incidência de fungos nos grãos de arroz (Oryza sativa) comercializado no município de Soure, Marajó, que podem apresentar ou não algum tipo de contaminação prejudicial à saúde do consumidor. As amostras foram adquiridas durante o período de janeiro a outubro de 2019, em dois supermercados do município de Soure. Foram utilizadas amostras de arroz de $1 \mathrm{~kg}$, levando em consideração as marcas mais consumidas no município sendo: $1 \mathrm{~kg}$ de arroz polido tipo I (Tio João), $1 \mathrm{~kg}$ de arroz polido tipo I (Salvaterra), $1 \mathrm{~kg}$ de arroz integral (Natu Qualy) e $1 \mathrm{~kg}$ de arroz polido tipo II (Gama Lopes), avaliando a condição da embalagem, o estado de conservação, data de fabricação e validade na hora da coleta. O preparo das amostras e identificação, assim como o isolamento e o plaqueamento, foram feitos na cabine de segurança biológica e submetidos a luz UV, impedindo a contaminação externa; logo após, foi realizada a incubação; em seguida, a observação das amostras foi efetuada com o auxílio do microscópio para a identificação dos gêneros fúngicos; para finalizar, foi feita a análise dos gêneros mais comuns encontrados nas amostras. Após as análises dos meses de janeiro a outubro de 2019, foi verificado a incidência fúngica nas amostras coletadas, sendo: Aspergillus $\mathrm{sp}$, mucor sp, Fusarium sp, Rhizopus sp, Curvularia sp, Chaetomium sp, Penicillium $\mathrm{sp}$, leveduras, até mesmo ácaros e uma espécie de inseto Oryzophagus oryzae, conhecido como gorgulho-aquático. Esses microrganismos podem causar prejuízos à saúde do consumidor, seja em pequenas ou grandes concentrações, a curto ou longo prazo e, mesmo sendo feito o cozimento, as toxinas podem continuar ativas nos grãos, contaminando quem o consome.

Palavras-chave: Arroz, saúde do consumidor, incidência, contaminação, fungos. 


\section{INTRODUÇÃO}

O arroz (Oryza sativa) é considerado uma gramínea da família Poáceae, que está inserido na classe Liliopsida, pertencente a ordem Poales, que fica no grupo das monocotiledôneas, contido na divisão das Magnoliófitas (PACHECO, 2008), possuindo aproximadamente vinte espécies, sendo a $O$. sativa a mais cultivada (JULIANO, 1993). Se tratando desse grão, não se sabe ao certo sua origem, porém, supõe-se que seja da Índia ou da China, mas há relatos de que por volta de 2.800 a.C. o arroz era considerado a planta sagrada do imperador da China (FLANDRIN \& MONTANARI, 1998).

Muitos cientistas e alguns historiadores descrevem a região do sudeste da Ásia como sendo o local de origem do arroz. Nesse local foi encontrado duas formas iniciais silvestres, apresentadas na literatura como as pioneiras do arroz cultivado: Oryza rufipogon, vinda da Ásia, que deu origem a espécie Oryza sativa; e a Oryza barthii (Oryza breviligulata), que veio da África Ocidental e deu origem à espécie Oryza glaberrima (CORDEIRO, 2007). Este grão chegou ao Brasil trazido pela frota de Pedro Álvares Cabral, no entanto o seu cultivo só foi primeiramente descrito em território brasileiro após o ano de 1530, junto a capitania de São Vicente. Logo após, foi espalhado pelo litoral do país, sendo encontrado em pequenas lavouras da região Nordeste principalmente (PEREIRA, 2002).

O grão de arroz (Figura 1) é composto pela casca, constituída pela pálea e a lema, que corresponde a $20 \%$ do peso do grão; pela cariopse, constituída pelo pericarpo, tegumento, aleuroma, endosperma de amido; e, também, pelo embrião, que é composto pelo escutelo, epiblasmo, plúmula e radícula (WALTER et al., 2008). 
Figura 1: Estrutura do grão de arroz (MCLEAN et al., 2002)

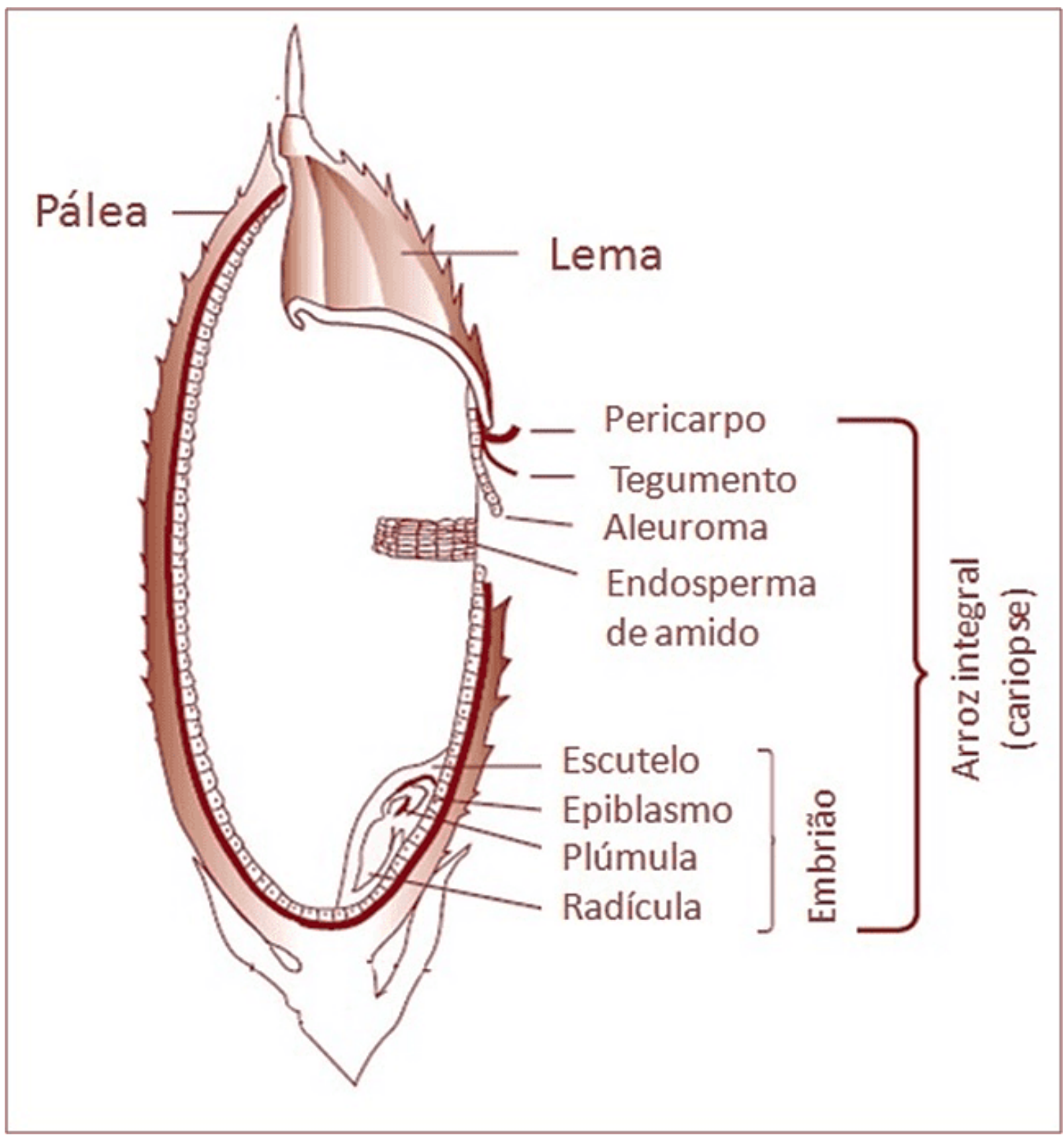

Fonte: Rice Almanac: Source Book for the Most Important Economic Activity on Earth.

Tratando da sua estrutura, de acordo com o Ministério da Agricultura, Pecuária e Abastecimento (MAPA), o arroz que possui a casca natural é aquele que não vai passar por nenhum preparo ou qualquer tipo de processo tecnológico. Já o arroz conhecido como beneficiado, é aquele considerado maduro e que já passou por algum processo de beneficiamento, estando agora sem sua casca. Outro tipo de arroz é o 
descascado ou integral, que ao passar pelo beneficiamento, tem retirada sua casca, possuindo apenas o farelo que é rico em fibras, lipídeos, vitaminas e minerais (HUNT; JOHNSON; JULIANO, 2002; WYATT; TRIANA-TEJAS, 1994). O arroz polido passa pelo beneficiamento e dele são retirados o germe (embrião), o pericarpo e a maior parte da camada interna (aleurona) (BRASIL, 2009; WALTER; MARCHEZAN; AVILA, 2008). O arroz do tipo parboilizado passou pelo processo de parboilização, que vem antes do descasque e polimento, onde fica a uma temperatura maior que $58^{\circ} \mathrm{C}$ em água, após vem a gelatinização do amido e ao final a secagem, onde algumas substâncias, como minerais e as vitaminas acabam ficando no centro do grão, o que aumenta consideravelmente seu valor nutritivo (BRASIL, 2009; FERREIRA \& YOKOYAMA, 1999).

Esse cereal é considerado o alimento mais básico e mais consumido de metade da população do planeta. No Brasil, não é diferente, o arroz é o alimento mais importante na dieta do brasileiro, da mesma forma em outros países como o Peru, a Colômbia e na América Latina (HOELTZ, 2009). Estima-se que a produção mundial do grão seja mais de 475 milhões de toneladas, onde 8,3 milhões são produzidas somente no Brasil (USDA/FAS, 2015). Sua produção no país é concentrada na região sul, no estado do Rio Grande do Sul, conhecido por iniciar o processo de parboilização. A partir do início desse processo, houve um aumento na produção e no consumo desse tipo de arroz nos últimos anos (LUZ; TREPTOW, 1994; SAFRAS; MERCADO, 1998; COELHO et al., 1999).

Os tipos de arroz mais consumidos no Brasil são o polido, o integral e o parboilizado (EMBRAPA, 1999). O arroz mais consumido, com cerca de $70 \%$, é o arroz branco polido, em segundo lugar se encontra o arroz parboilizado, com aproximadamente $25 \%$, já o arroz integral ficou com 3 a $4 \%$ do consumo pela população brasileira (ELIAS et al., 2012). De acordo com o MAPA, o arroz consegue suprir $20 \%$ de energia e $15 \%$ de proteína que um adulto precisa diariamente, além de conter um grande valor nutricional, possuindo também grande valor energético. Além disso, esse cereal possui sais minerais (fosfato, ferro e cálcio), vitaminas do complexo B (arroz integral), 
baixo teor de sódio e contém uma pequena quantidade de gorduras (BASSINELLO \& CASTRO, 2004).

Seu cultivo é principalmente realizado de forma irrigada, o que faz com que o arroz seja bastante propício a umidade, criando um ambiente adequado para que haja a contaminação do grão por alguns microrganismos como por exemplo: os fungos (COELHO et al., 1999). Eles são considerados como organismos eucariontes, unicelulares ou multicelulares, podendo ser cosmopolitas, isto é, são encontrados em qualquer parte do planeta, como: no ar, na água, sobre os animais, no solo, em vegetais vivos, nos produtos alimentícios e industriais, na matéria orgânica em decomposição e entre outros locais (TRABULSI et. al., 1999).

É comum encontrar fungos no arroz, esses microrganismos podem afetar as culturas do grão e, consequentemente, acabar afetando os consumidores. Alguns deles produzem micotoxinas, que são metabólitos secundários, ou seja, substâncias tóxicas que prejudicam tanto humanos quanto animais (HOELTZ, 2009; LORINI; MIIKE; SCUSSEL, 2002). O que se torna preocupante é o fato desse alimento ser um excelente substrato para a produção destes fungos, pois eles encontram condições adequadas para crescer e se desenvolver (KJER et al., 2010). Isso ocorre por fatores como umidade e altas temperaturas que influenciam na produção de fungos no arroz (PITT \& HOCKING, 1997). Outro fator que possibilita um substrato ideal para o crescimento e desenvolvimento desses contaminantes, se dá por conta de o arroz ser rico em carboidratos, facilitando a contaminação (COELHO et al., 1999).

Esse cereal pode ser infectado, antes mesmo que ocorra a colheita, por fungos como o Fusarium sp., ou após a colheita, durante as fases de secagem ou em seu armazenamento, ficando sujeito a infecção por Aspergillus sp. e Penicillium sp. (PITT \& HOCKING, 2009). A partir do momento em que os grãos são infectados pelos fungos, ocorre o risco de que haja também a contaminação pelas toxinas, que podem causar diversos problemas graves como: carcinogenicidade e imunossupressão (KIESSLING, 1986; OSBORNE, 1982). Os gêneros que são mais encontrados no arroz são: Aspergilllus sp., Penicillium sp. e Fusarium sp. Apesar de o arroz passar por vários processamentos, levando o fungo a ser eliminado superficialmente no grão, 
as toxinas produzidas por eles podem permanecer ativas, pois conseguem suportar altas temperaturas, não sendo degradadas facilmente (KIESSLING, 1986; PITT; HOCKING, 1997). Dessa forma, ingerir alimentos contaminados por fungos pode ocasionar muitos prejuízos à saúde do consumidor. Pelo fato de ser bastante consumido pela população brasileira, torna-se importante avaliar a presença de contaminações fúngicas no arroz (Polido, Integral e Polido tipo II) comercializado no município de Soure. O objetivo deste trabalho é avaliar a incidência de fungos nos grãos de arroz Oryza sativa, comercializado em Soure, na llha do Marajó, identificando os gêneros fúngicos presentes nos tipos de arroz e verificando quais são os gêneros mais comuns em todas as amostras.

\section{METODOLOGIA}

\subsection{AMOSTRAGEM}

Foram feitas 5 coletas no período de janeiro a setembro de 2019, um mês sim e outro não (janeiro-sim, fevereiro-não), com 14 amostras adquiridas em dois supermercados comerciais do município de Soure, supermercado 1 e supermercado 2. Foram utilizadas amostras de arroz de $1 \mathrm{~kg}$, levando em consideração as marcas mais consumidas no município, sendo: $1 \mathrm{~kg}$ de arroz polido tipo I (Tio João), $1 \mathrm{~kg}$ de arroz polido tipo I (Salvaterra), $1 \mathrm{~kg}$ de arroz integral (Natu Qualy) e $1 \mathrm{~kg}$ de arroz polido tipo II (Gama Lopes). Avaliando, também, a condição da embalagem, o estado de conservação desse arroz, data de fabricação e validade na hora da coleta. Logo após, o isolamento e a análise foram feitos no Laboratório de microbiologia e parasitologia da Universidade Federal do Pará Campus do Marajó em Soure, sendo avaliada a incidência de fungos nas amostras coletadas nos dois supermercados do município. 
Figuras 2: A: $1 \mathrm{~kg}$ de arroz polido tipo I (Tio João); B: $1 \mathrm{~kg}$ de arroz polido tipo I (Salvaterra); C: $1 \mathrm{~kg}$ de arroz integral (Natu Qualy); D: $1 \mathrm{~kg}$ de arroz polido tipo II (Gama Lopes).
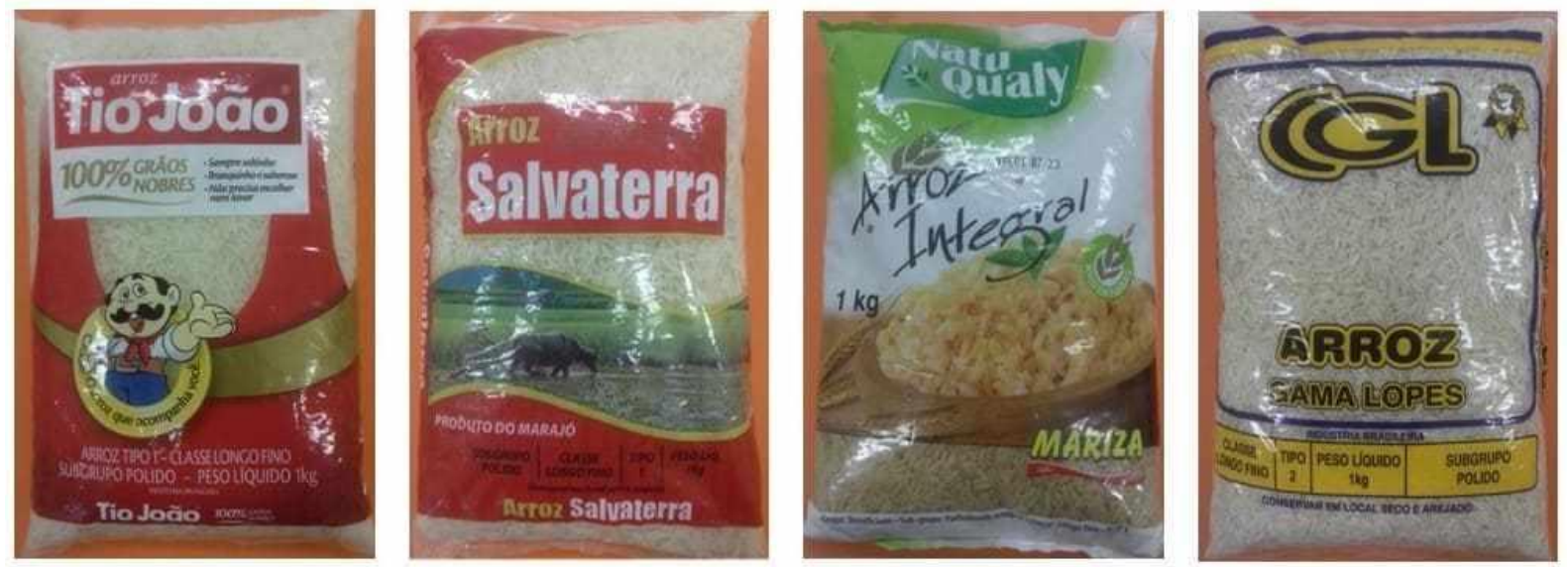

Fonte: Elaborada pela autora.

\subsection{PREPARO DAS AMOSTRAS E IDENTIFICAÇÃO}

Antes de abrir as embalagens, elas foram colocadas dentro da cabine de segurança biológica e submetidas a luz Ultravioleta para evitar que não ocorra a contaminação. Em seguida, a área cortada para a retirada dos grãos foi desinfetada superficialmente com álcool $70 \%$ para impedir qualquer influência do ambiente na amostra. Foram utilizadas uma tesoura e uma pinça desinfectadas com álcool 70\% para abertura e a remoção dos grãos. Após a abertura das embalagens, foi feita a identificação nas placas com as datas de plaqueamento e as letras iniciais de cada marca de arroz: A. T. Jo; A. S; A. G. L; A. I. N. Q. (Arroz Tio João, Arroz Salvaterra, Arroz Gama Lopes e Arroz Integral Natu Qualy). 
Figuras 3: A: Cabine de segurança com luz Ultravioleta; B: Álcool 70\%; C: Tesoura; D: Pinça; E: Identificação.
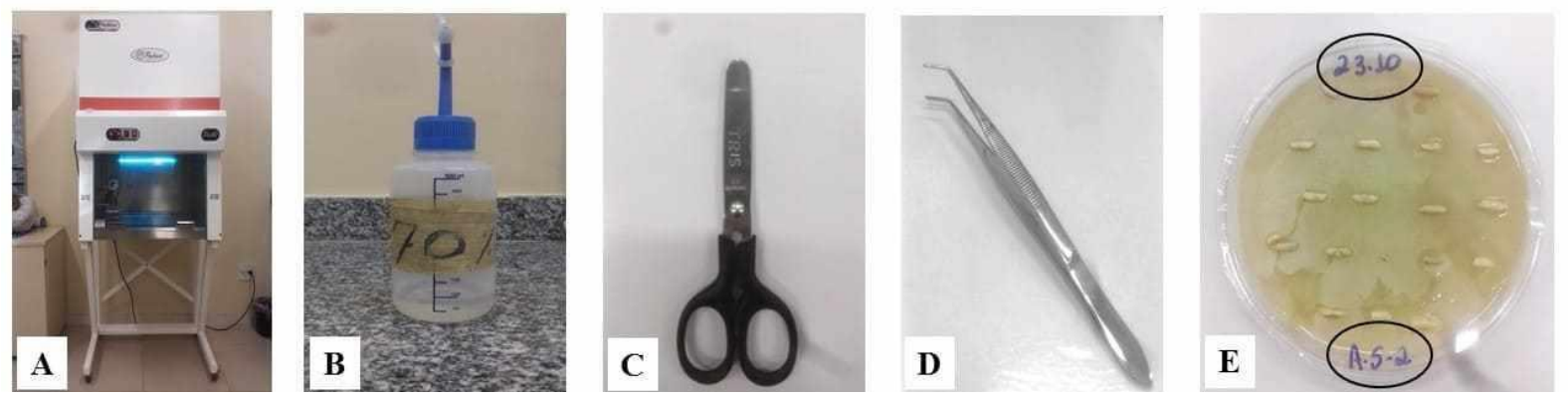

Fonte: Elaborada pela autora.

\subsection{ISOLAMENTO E PLAQUEAMENTO}

O procedimento de isolamento foi realizado dentro da cabine de segurança biológica para que não haja interferência do meio externo, vetando uma possível contaminação da amostra. Foi usado o método de plaqueamento por semeadura em superfície para o isolamento. Dessa forma, foram selecionados 20 grãos, aleatoriamente, sem desinfestação e semeados em Placas de Petri descartáveis (20 grãos/Placa de Petri), contendo o meio de cultura de Ágar Batata Dextrose (BDA) para o crescimento dos possíveis fungos, com 2,9\% da embalagem do arroz polido tipo I Tio João, 3,4\% da embalagem do arroz polido tipo I Salvaterra, 2,5\% da embalagem do arroz polido tipo II Gama Lopes e 3,7\% da embalagem do arroz integral Natu Qualy, sendo que, foram feitas repetições de cada amostra coletada. Esse meio de cultura é feito a partir de $39 \mathrm{~g}$ de BDA pesado em um baker para um litro de água destilada, que foi levado até a autoclave por 30 minutos. Logo após, quando ficou pronto, foi retirado da autoclave e conduzido até a cabine de segurança biológica para ser posto nas Placas Petri descartáveis. E, para finalizar, as amostras, já semeadas em meio de cultura, foram vedadas com fita, impedindo a contaminação pelo meio externo. 
Figuras 4: A: Cabine de Segurança Biológica; B: Grãos semeados em meio de cultura de BDA; C: Baker com 39g de BDA pesado e um litro de água destilada; D: Autoclave; E: Cabine de segurança com os meios de cultura em Placa de Petri; F: Fita.
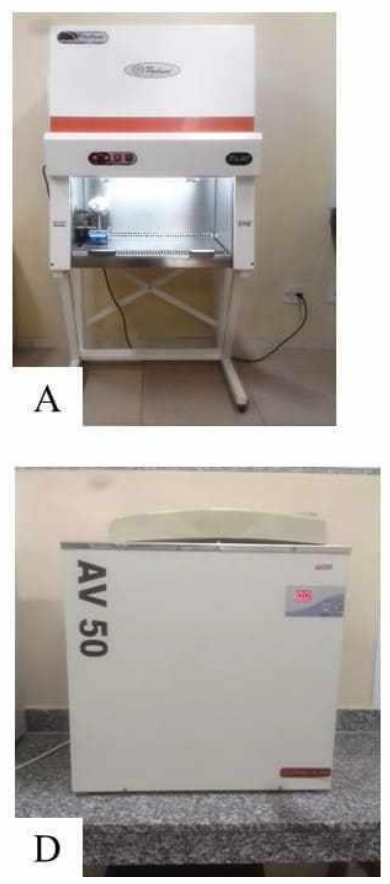
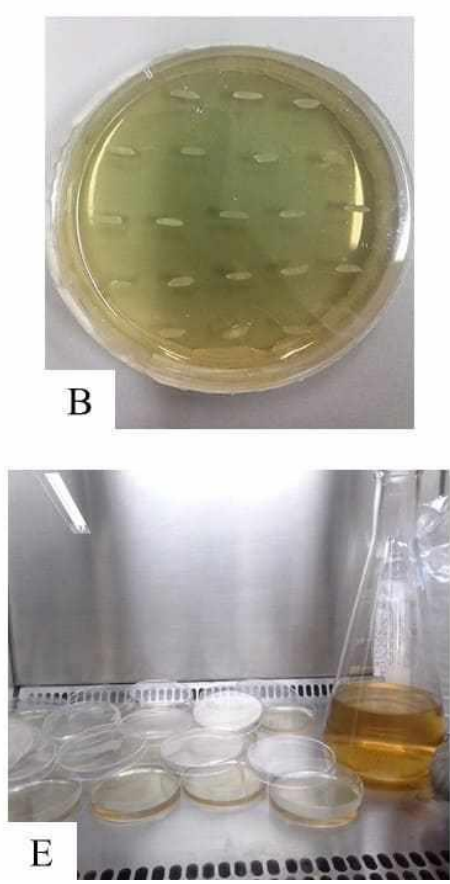
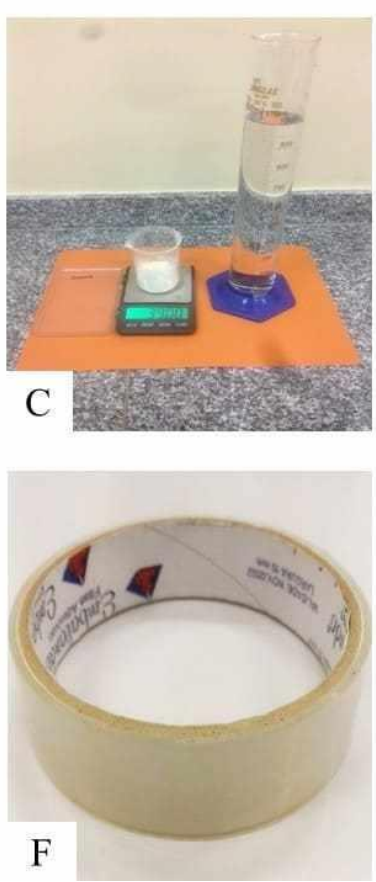

Fonte: Elaborada pela autora.

\subsection{INCUBAÇÃO E OBSERVAÇÃO}

Logo após o isolamento e plaqueamento, as amostras, que já estão devidamente vedadas, passaram de cinco a sete dias em incubação para se obter o crescimento e desenvolvimento das colônias de fungos nas placas com o BDA. Após o período de incubação, foi realizada a identificação dos gêneros fúngicos presentes nos grãos. Esse procedimento foi feito dentro da cabine de segurança, impossibilitando qualquer contaminação que possa acontecer. Para a avaliação das características microscópicas, foram retirados os micélios dos fungos crescidos nas placas com o auxílio de uma pequena fita adesiva, em seguida, a pequena fita, já com o micélio do fungo, foi colocada sobre uma lâmina com identificação, no entanto foi necessária a utilização de um corante (uma gota de lactofenol azul de algodão) para a melhor visualização, logo após, uma lamínula foi colocada sobre a lâmina com o corante, 
pressionando-a sobre a amostra que foi utilizada no microscópio óptico, a fim de visualizar os gêneros fúngicos.

Figuras 5: A: Identificação; B: Cabine de Segurança; C: Fita com o micélio do fungo e uma gota de corante (lactofenol azul de algodão); D: Lamínula sobre o micélio e o corante; E: Microscópio.
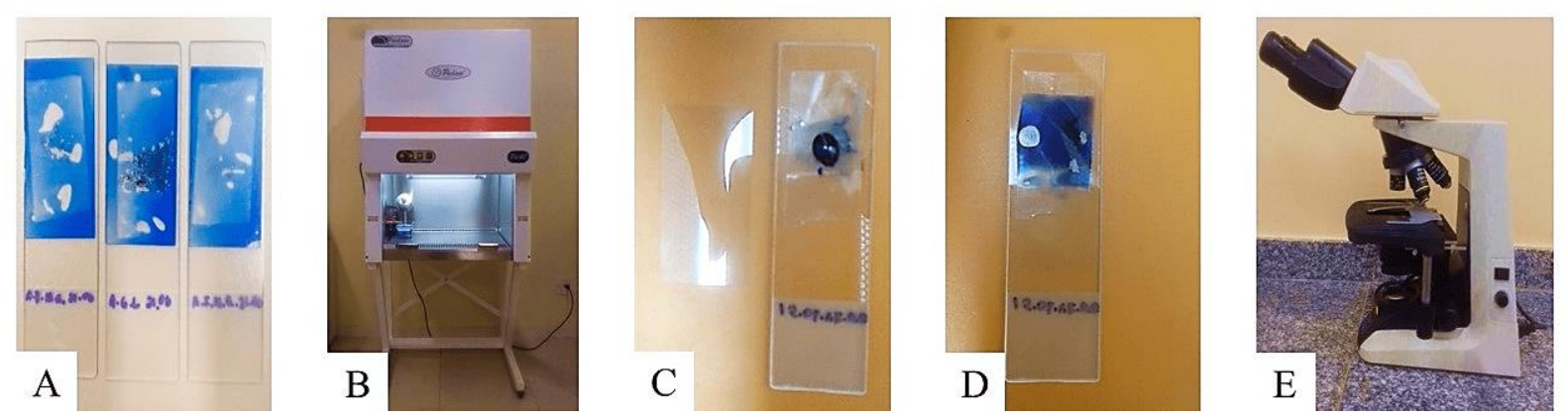

Fonte: Elaborada pela autora.

\subsection{TRANSFERÊNCIA E ISOLAMENTO DA COLÔNIA}

Posteriormente a observação das lâminas, se encontrados os agentes fúngicos no arroz, eles foram transferidos e isolados em outro meio de cultura para observação. O procedimento foi feito no interior da cabine de segurança biológica, evitando a contaminação, dessa forma, utilizou-se a alça de Drigalsky de platina para a retirada do micélio da placa contaminada e, em seguida, foi posto na placa com o meio de cultura BDA e, posteriormente, foi fechada com fita. 
Figuras 6: A: Placa de Petri com meio de cultura BDA; B: Cabine de segurança biológica; C: Alça de Drigalsky Platina; D: Fita.
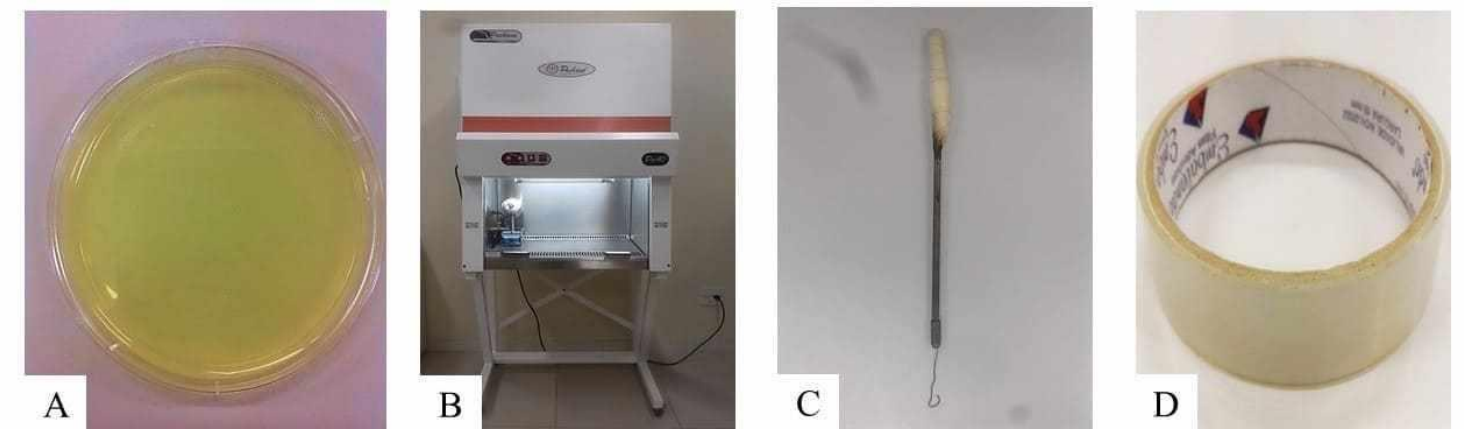

Fonte: Elaborada pela autora.

\subsection{ANÁLISE DOS GÊNEROS FÚNGICOS MAIS COMUNS}

Para verificar quais os gêneros fúngicos mais frequentes em todas as amostras. Os resultados foram organizados em tabelas e realizada a comparação entre os dados obtidos em cada um dos tipos de arroz analisados, com a utilização da literatura de livros.

\section{RESULTADOS}

\begin{tabular}{|c|c|c|c|c|}
\hline \multirow{2}{*}{$\begin{array}{l}\text { MESES } \\
/ 2019\end{array}$} & \multicolumn{4}{|l|}{ ARROZ } \\
\hline & $\begin{array}{l}\text { ARROZ } \\
\text { TIPO I } \\
\text { (Arroz Tio } \\
\text { João) }\end{array}$ & $\begin{array}{l}\text { ARROZ TIPO I } \\
\text { (Arroz Salvaterra) }\end{array}$ & $\begin{array}{l}\text { ARROZ TIPO II } \\
\text { (Arroz Gama } \\
\text { Lopes) }\end{array}$ & $\begin{array}{l}\text { ARROZ } \\
\text { INTEGRAL } \\
\text { (Arroz Natu } \\
\text { Qualy) }\end{array}$ \\
\hline JAN & $\begin{array}{l}\text { Aspergilus } \\
\text { sp.,; } \\
\text { Penicillium } \\
\text { sp.,; Mucor } \\
\text { sp.,; } \\
\text { Fusarium }\end{array}$ & 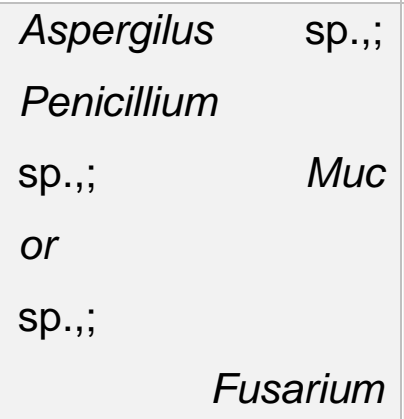 & $\begin{array}{l}\text { Não foi } \\
\text { encontrado } \\
\text { para venda }\end{array}$ & $\begin{array}{lr}\text { Aspergilus } & \text { sp.,; } \\
\text { Penicillium } & \\
\text { sp.,; } & M \\
\text { ucor } & \\
\text { sp.,; } & F u \\
\text { sarium } & \text { sp.,; }\end{array}$ \\
\hline
\end{tabular}




\begin{tabular}{|c|c|c|c|c|}
\hline & $\begin{array}{l}\text { sp.,; } \\
\text { Rhizopus sp. }\end{array}$ & $\begin{array}{l}\text { sp.,; } \\
\text { pus sp. }\end{array}$ & & $\begin{array}{l}\text { Rhizopus sp. } \\
\text { Curvularia sp }\end{array}$ \\
\hline MAR & $\begin{array}{l}\text { Aspergilus } \\
\text { sp.,; } \\
\text { Penicillium } \\
\text { sp.,; Mucor } \\
\text { sp.,; } \\
\text { Fusarium } \\
\text { sp.,; }\end{array}$ & $\begin{array}{l}\text { Não foi } \\
\text { encontrado } \\
\text { para venda }\end{array}$ & $\begin{array}{lr}\text { Aspergilus } & \text { sp.,; } \\
\text { Penicillium } & \\
\text { sp.,; } & M \\
\text { ucor } & \\
\text { sp.,; } & \mathrm{Cu} \\
\text { rvularia sp. } & \end{array}$ & $\begin{array}{ll}\text { Aspergilus } & \\
\text { sp.,; } & M \\
\text { ucor } & \\
\text { sp.,; } & F u \\
\text { sarium } & \\
\text { sp.,; } & R \\
\text { hizopus sp. } & \\
& \\
\text { Chaetomium } & \\
\text { sp. } & \end{array}$ \\
\hline MAI & $\begin{array}{l}\text { Aspergilus } \\
\text { sp.,; } \\
\text { Penicillium } \\
\text { sp.,; } \\
\text { Fusarium sp. }\end{array}$ & $\begin{array}{l}\text { Não foi } \\
\text { encontrado } \\
\text { para venda }\end{array}$ & $\begin{array}{l}\text { Aspergilus sp.,; } \\
\text { Penicillium } \\
\text { sp.,; } \\
\text { ucor } \\
\text { sp.,; } \\
\quad \text { Rhizopus sp. }\end{array}$ & $\begin{array}{l}\text { Não foi } \\
\text { encontrado } \\
\text { venda }\end{array}$ \\
\hline JUL & $\begin{array}{l}\text { Aspergilus } \\
\text { sp.,; } \\
\text { Penicillium } \\
\text { sp.,; } \\
\quad \text { Mucor sp.,; }\end{array}$ & $\begin{array}{l}\text { Não } \\
\text { encontrado } \\
\quad \text { para venda }\end{array}$ & $\begin{array}{l}\text { Aspergilus } \\
\text { sp.,; } \quad M u \\
\text { cor } \\
\text { sp.,; } \\
\quad \text { Rhizopus sp. }\end{array}$ & $\begin{array}{l}\text { Não foi } \\
\text { encontrado } \\
\text { venda }\end{array}$ \\
\hline SET & $\begin{array}{l}\text { Aspergilus } \\
\text { sp.,; } \\
\text { Rhizopus sp. }\end{array}$ & $\begin{array}{l}\text { Aspergilus } \\
\text { sp.,; } \\
\text { ucor } \\
\text { sp.,; } \\
\quad \text { Fusarium sp. }\end{array}$ & $\begin{array}{l}\text { Aspergilus } \\
\text { sp.,; } \\
\text { Mucor } \\
\text { sp.,; } \\
\text { Rhizopus sp. }\end{array}$ & $\begin{array}{l}\text { Aspergilus } \\
\text { sp.,; } \\
\text { ucor } \\
\text { sp.,; } \\
\text { Rhizopus sp. } \\
\text { Chaetomium } \\
\text { sp. }\end{array}$ \\
\hline
\end{tabular}


Após as análises do mês de janeiro a setembro de 2019, foram identificados os seguintes gêneros fúngicos, nas diferentes marcas de arroz: Aspergillus sp., Mucor sp., Fusarium sp., Rhizopus sp., Curvularia sp., Chaetomium sp., Penicillium sp., sendo que, o gênero mais abundante foi o Aspergillus $s p$. Na tabela 1 está representado os gêneros fúngicos encontrados em cada tipo de arroz, porém em alguns meses de amostragem não foi possível realizar a análise fúngica devido alguns tipos de arroz não se encontrarem disponíveis para venda.

Fonte: Elaborado pelas próprias autoras.

A partir das observações, o arroz Polido tipo I, da marca Tio João, apresentou os seguintes gêneros fúngicos: Aspergillus sp., Mucor sp., Fusarium sp., Rhizopus sp., Penicillium sp. e leveduras não identificadas.

Figuras 7: A: Aspergillus sp., aumento de 40x; B: Mucor sp., aumento de 40x; C: Fusarium sp., aumento de 40x; D: Rhizopus sp., aumento de 40x; E: Penicillium sp., aumento de 40x; F: Leveduras sem aumento.
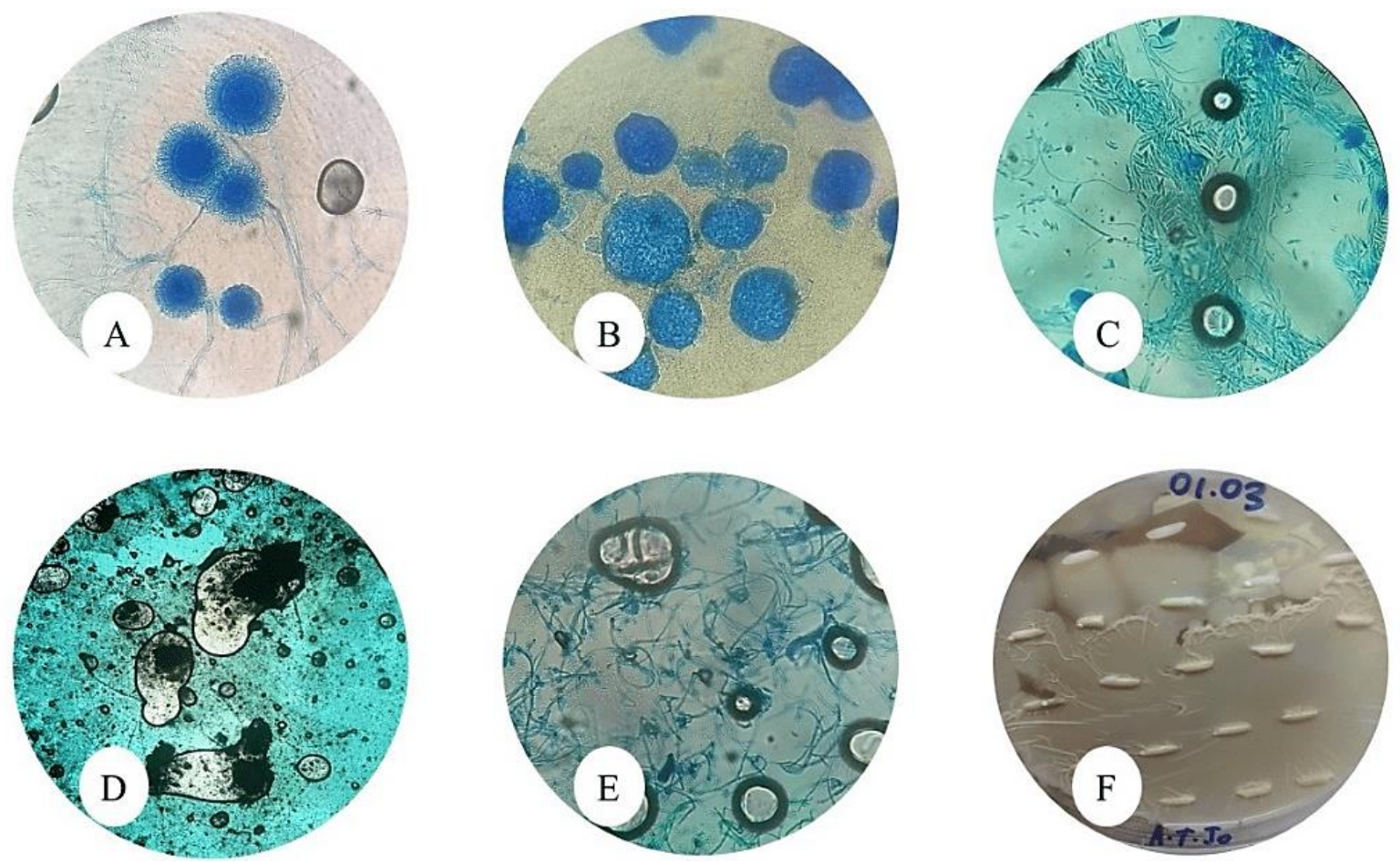

Fonte: Elaborada pela autora. 
O arroz Polido tipo I, da marca Salvaterra, apresentou os respectivos gêneros fúngicos: Aspergillus sp., Rhizopus sp., Mucor sp., Penicillium sp., Fusarium sp. leveduras e uma espécie de ácaro.

Figuras 8: A: Aspergillus sp., aumento de 40x; B: Rhizopus sp., aumento de 40x; C: Mucor sp., aumento de 40x; D: Penicillium sp., aumento de 40x; E: Fusarium sp., aumento de 40x; F: Leveduras sem aumento; G: Ácaros aumento de 40x.

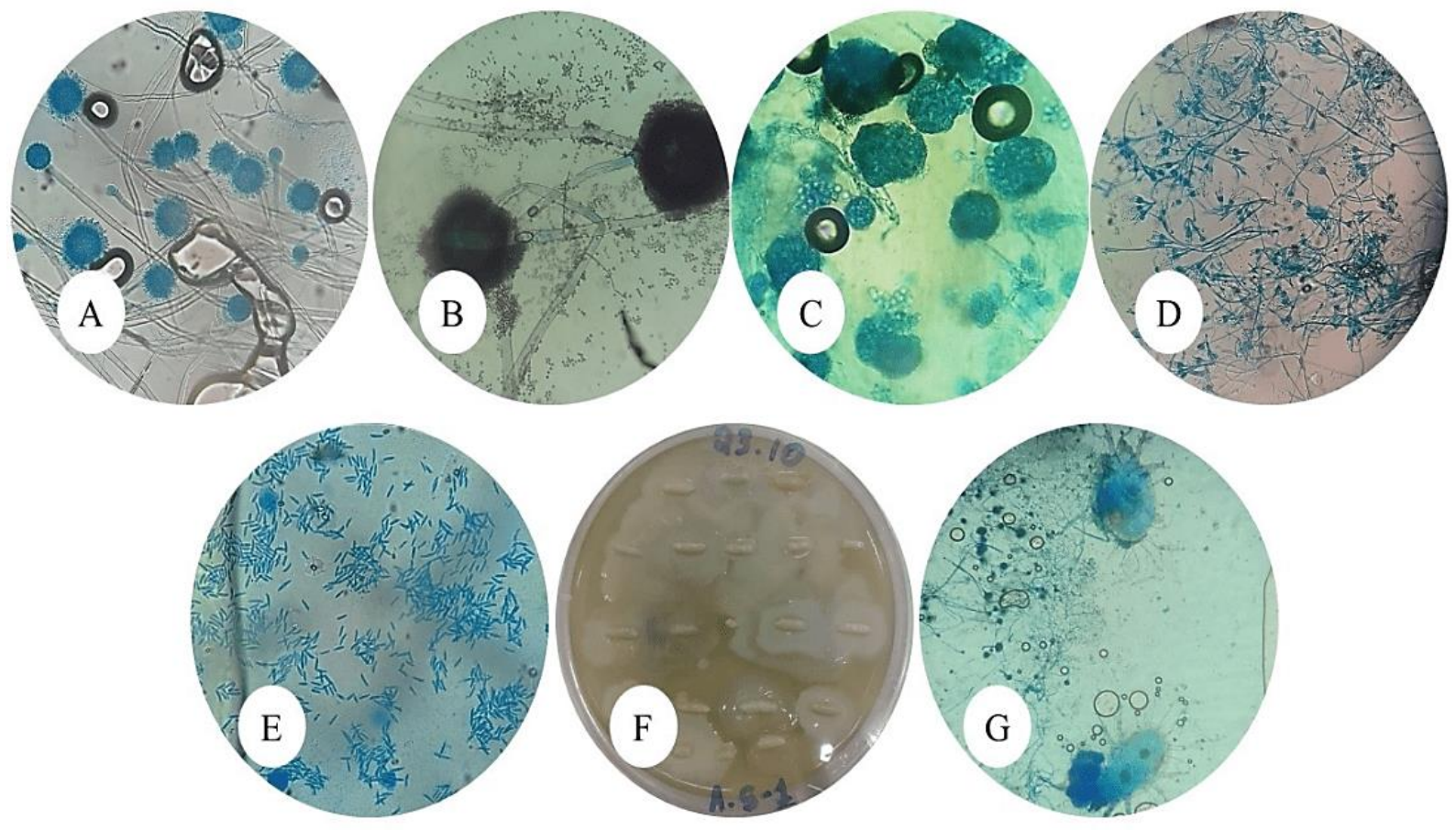

Fonte: Elaborada pela autora.

Já o arroz Polido tipo II, da marca Gama Lopes, apresentou os seguintes gêneros fúngicos: Aspergillus sp., Curvularia sp., Rhizopus sp., Fusarium sp., Penicillium sp., Chaetomium sp. e leveduras. 
Figuras 9: A: Aspergillus sp., aumento de 40x; B: Curvularia sp., aumento de 40x; C: Rhizopus sp., aumento de 40x; D: Fusarium sp., aumento de 40x; E: Penicillium sp., aumento de 40x; F: Chaetomium sp., aumento de 40x; G: Leveduras sem aumento.

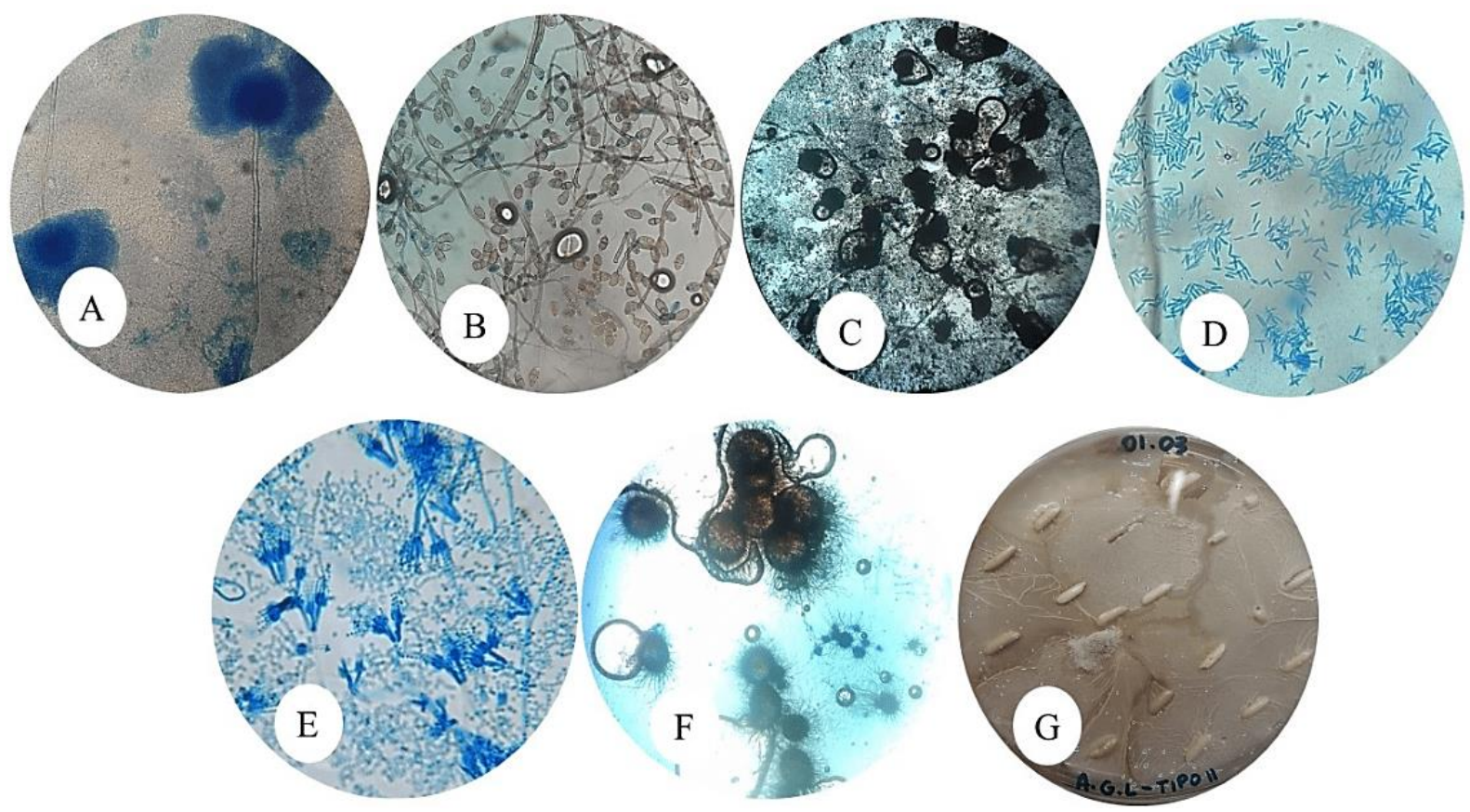

Fonte: Elaborada pela autora.

Se tratando do arroz Integral, da marca Natu Qualy, esse apresentou contaminação em 100\% dos grãos analisados, com os seguintes gêneros: Aspergillus sp., Penicillium sp., Mucor sp., Rhizopus sp., Curvularia sp. e leveduras. Além disso, foi encontrada uma espécie de inseto Oryzophagus oryzae conhecido como gorgulhoaquático. 
Figuras 10: A: Aspergillus sp., aumento de 40x; B: Penicillium sp., aumento de 40x; C: Mucor sp., aumento de 40x; D: Rhizopus sp., aumento de 40x; E: Curvularia sp., aumento de 40x; F: Leveduras em Laranja sem aumento; G: Oryzophagus oryzae (gorgulho-aquático) sem aumento.

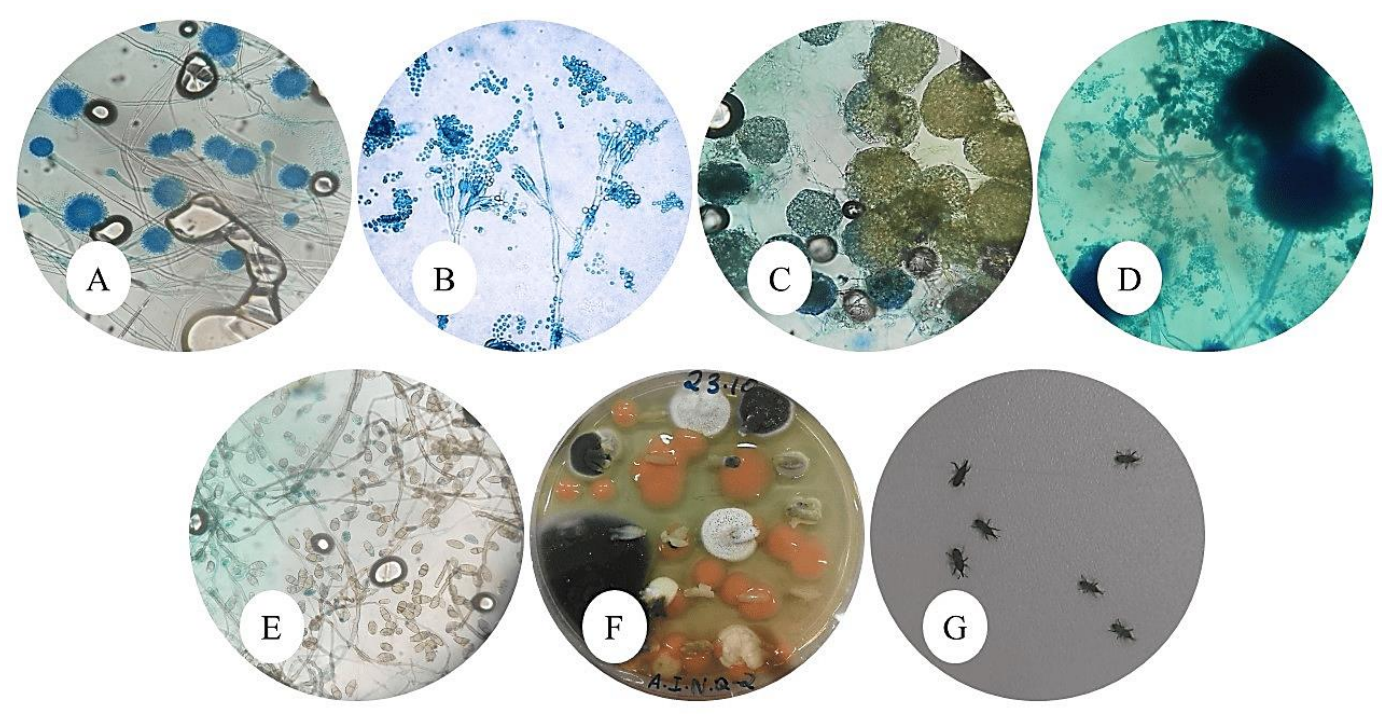

Fonte: Elaborada pela autora.

De uma forma geral, ao comparar os resultados encontrados em cada tipo de arroz, foi possível observar que alguns gêneros fúngicos foram comuns em todas as amostras, sendo eles: Aspergillus sp.,; Penicillium sp. e Rhizopus sp.

Figuras 11: A: Aspergillus sp., aumento de 40x; B: Penicillium sp., aumento de 40x; C: Rhizopus sp., aumento de 40x.
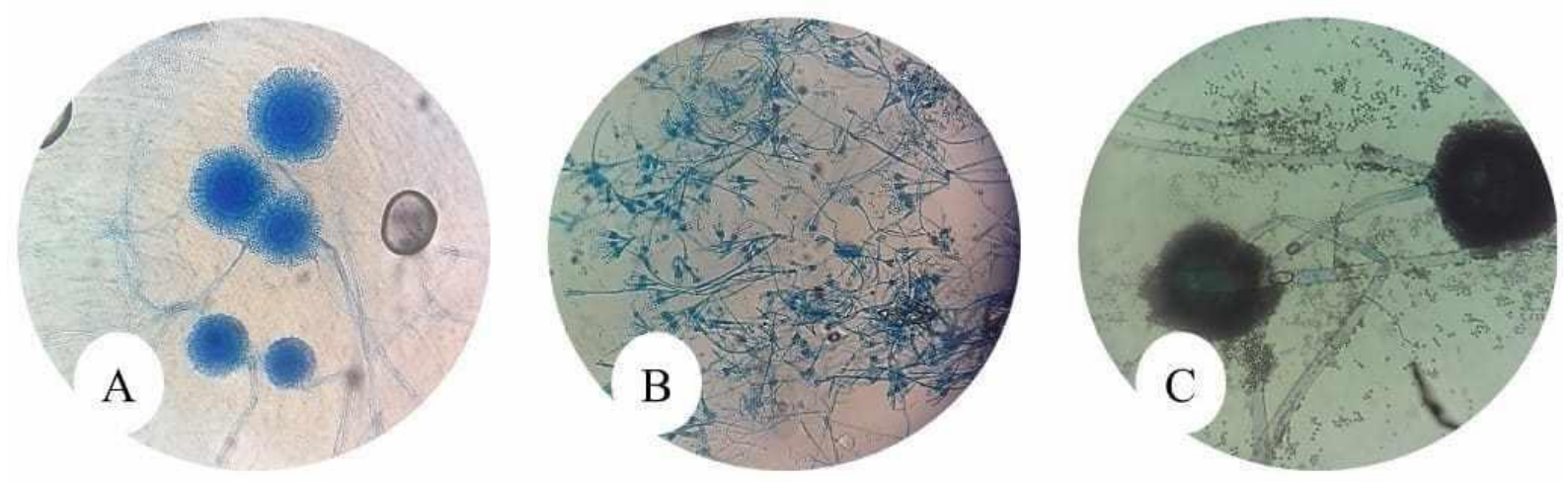

Fonte: Elaborada pela autora. 


\section{DISCUSSÃO}

Segundo os resultados da presente pesquisa, as amostras de arroz apresentaram uma alta quantidade de fungos, tanto filamentosos quanto unicelulares. Resultado parecido foi encontrado na pesquisa realizada por Lobo et al. (2010) que objetivou investigar a qualidade microbiológica no arroz comercializado em Goiânia e encontrou em todas as amostras analisadas a ocorrência dos gêneros Aspergillus sp., Penicillium sp. e Fusarium sp. Essa contaminação também foi evidenciada na pesquisa desenvolvida por Guimarães et al. (2010) que teve como objetivo avaliar dois diferentes métodos usados em laboratório, tendo como finalidade selecionar o mais sensível na detecção de fungos em arroz exposto a diferentes doses de irradiação gama, e os gêneros fúngicos detectados nas amostras de arroz branco polido foram de Penicillium sp., Aspergillus sp., Cladosporium sp., Fusarium sp. e Trichoderma sp..

A contaminação fúngica evidenciada nos grãos de arroz do presente estudo possivelmente ocorreu no processo de beneficiamento desse cereal, uma vez que, todas as amostras apresentaram contaminação fúngica. Segundo Pitt et al. (2013), quando os grãos são colhidos úmidos e ocorre uma demora na secagem, pode acontecer um aumento elevado na proliferação desses organismos. Athié et al. (1998) afirma que os fungos que atacam os grãos se dividem em dois grupos: os fungos de campo e os de armazenamento. Os de campo são aqueles que vão contaminar os grãos antes que ocorra a colheita, pois necessitam que a umidade esteja acima de $30 \%$. Puzzi, (2000) relata que os gêneros mais encontrados no grupo de campo são: Alternaria sp., Cladosporium sp., Fusarium sp., Helmintosporium sp. e Pullularia sp. Já os fungos de armazenamento acabam contaminando os grãos após a colheita, nesse caso eles necessitam que a umidade esteja entre 13 e $18 \%$. O mesmo autor também descreve que no grupo de armazenamento são encontrados os gêneros: Aspergillus sp. e Penicillium sp. Contudo, Rovaris et al. (2003) descreve um terceiro grupo mencionado por Pelhate, (1979), chamado de intermediário, onde foram encontrados os gêneros: Cladosporium sp., Aureobasidium sp., Mucor sp., Trichoderma sp. e leveduras. 
Outro fator que pode ter sido essencial para a contaminação fúngica no arroz, é o armazenamento em silos. Para Fonseca, (2019) o armazenamento de alimentos como o arroz é considerado um ótimo substrato para o crescimento e a proliferação de fungos, isso ocorre principalmente quando não é feito o armazenamento adequado ou quando ele é desprezado e desconhecido. Os fungos são considerados por Banks \& Fields, (1995); Brasil, (2009) como essenciais para a deterioração do arroz que está armazenado em silos, pois eles podem causar vários prejuízos, como: alterações que ocorrem na composição química desse cereal, o aquecimento e emboloramento dos grãos, a produção de toxinas e outros danos.

A contaminação do arroz também pode ocorrer devido a fatores como a temperatura, que quando ótimas, podem influenciar diretamente no crescimento e proliferação dos fungos nos grãos. Segundo o estudo feito por Park \& Bullerman, (1983), o arroz é, de fato, um meio adequado para a contaminação fúngica quando associado a esse fator. Conforme a observação desses autores, temperaturas de $25^{\circ} \mathrm{C}$ permitiram $\mathrm{O}$ crescimento de Aspergillus sp.

Além dos fungos, as amostras de arroz também apresentaram ácaros e uma espécie de inseto Oryzophagus oryzae, conhecido como gorgulho-aquático. Esse inseto pode ter se espalhado pelos grãos na embalagem e os fungos podem estar aderidos ao seu exoesqueleto, facilitando a contaminação fúngica neste cereal. De acordo com Castro et al. (1999), o desenvolvimento de fungos pode acontecer quando os insetos decompõem partes dos alimentos e transformam em gás carbônico e água, o que aumenta a umidade nos grãos, levando-os a serem infestados por fungos. Em climas temperados, os ácaros conseguem atacar todas as espécies de grãos, isso ocorre principalmente quando eles estão danificados, sendo encontradas mais de 80 espécies de insetos nos grãos que estão armazenados (MATTOS \& MARTINS, 2009).

Outro fator que prejudica a colheita desse cereal são os insetos, que causam prejuízos, além de influenciarem para que as toxinas sejam produzidas pelos fungos, conseguindo infectar os cultivos do arroz ainda em crescimento, facilitando a contaminação nos processos de beneficiamento, que podem ocorrer antes, durante 
ou até mesmo após o armazenamento dos grãos (ZLOTOWSKI et al., 2004; MALLMANN et al., 1994).

Dentre os gêneros fúngicos mais comuns encontrados durante a pesquisa, alguns são capazes de causar doenças aos consumidores, como é o caso do gênero Aspergillus sp. e Mucor sp. Para Dagenais \& Keller, (2009) o gênero Aspergillus sp., pode causar uma enfermidade chamada de aspergilose invasiva, que provoca uma infecção severa, progressiva e aguda, podendo ser fatal. Essa doença é disseminada por esse fungo nos pulmões e é levada até os rins, fígado, cérebro, trato gastrointestinal e outros órgãos, o que vai causar lesões necróticas e abcessos (PERSON et al., 2010). Já o gênero fúngico Mucorsp., pode acarretar uma doença chamada de mucormicose, que é considerada como uma forma de sinusite aguda invasiva, é uma infecção que rapidamente se espalha e afeta principalmente pacientes imunologicamente deprimidos, se não for tratada o mais rápido possível, pode se tornar fatal (SCHELL, 2000). Essa doença atinge a mucosa nasal com uma invasão secundária dos seios perinasais, órbita e cérebro (AKOZ \& AKAN, 1999). E apresenta sintomas como secreções nasais pútridas de cor preta, hiposmia, hiperemia conjutival, secreções oculares purulentas e visão turva a esquerda (MARIA et al., 2011).

\section{CONSIDERAÇÕES FINAIS}

A partir dos resultados obtidos na presente pesquisa, ficou evidenciado que as amostras coletadas em supermercados do município de Soure apresentaram abundante quantidade de fungos, com uma alta variedade de gêneros, sendo que alguns foram bastante comuns em todas as amostras analisadas. Logo, a contaminação fúngica no arroz, pode causar prejuízos à saúde do consumidor, seja em pequenas concentrações, a curto ou a longo prazo, mesmo sendo feito o cozimento, as toxinas podem continuar ativas nos grãos, contaminando quem o consome.

No entanto, destaca-se a importância de um melhor monitoramento para verificar a qualidade do arroz comercializado, visto que, esse grão pode estar sendo contaminado pelo processo de beneficiamento e, como foi verificado na presente 
pesquisa, ele pode causar danos à saúde do consumidor, provocando doenças, que se não forem tratadas podem ser tornar fatais.

\section{REFERÊNCIAS}

AKOZ T. CIVELEK B. AKAN M., Rhinocerebral mucormycosis: relate of two cases, Ann. Plast. Surg. 43 309-312, 1999.

ATHIÉ, I. et al. Conservação de grãos. Campinas: Fundação Cargill. 236p. 1998.

BASSINELLO, P. Z.; CASTRO, E. da M. Arroz como alimento. Informe Agropecuário, Belo Horizonte, v. 25, n. 222, p. 101-108, 2004.

BRASIL. Ministério da Agricultura, Pecuária e Abastecimento. Instrução Normativa ํㅡ 6, de 16 de fevereiro de 2009. Diário Oficial da República Federativa do Brasil, Poder Executivo, Brasília, DF, 18 fev. 2009, Seção 1, p. 3.

BANKS, H. J.; FIELDS, P. G. Physical methods for insect control in stored-grain ecosystems. In: JAYAS, D. S.; WHITE, N. D. G.; MUIR, W. E. (Ed.). Stored-grain ecosystems. New York: M. Dekker, p. 353-407, 1995.

CASTRO, E. da M. de: VIEIRA, N.R. de A.; RABELO, R.R.; SILVA, S.A. da. Qualidade de grãos em arroz. Santo Antônio de Goiás: Embrapa Arroz e Feijão, (Embrapa Arroz e Feijão. Circular Técnica, 34). 30p, 1999.

COELHO, C. S. P., BADIALE-FURLONG, E., AlMEIDA, T. L. Migração de Micotoxinas durante a Parboilização do Arroz. Brazilian Journal of Food Technology, v (1,2), p. 39-44, 1999.

CORDEIRO, A. C. C.; MOURÃO JÚNIOR, M. C.; MEDEIROS, R. D. de. Análise do agronegócio do arroz irrigado em Roraima - período 1981 a 2007. In: CONGRESSO BRASILEIRO DE ARROZ IRRIGADO, 6.; REUNIÃO DA CULTURA DO ARROZ IRRIGADO, 27., 2007, Porto Alegre. Anais...Porto Alegre: Orium, 2007. p. 719-721. 
DAGENAIS, T. R. T. e KELLER, N. P. Pathogenesis of Aspergillus fumigatus in Invasive Aspergillosis, Clinical Microbiology Reviews. pp. 447-465. 2009.

EMBRAPA. Qualidade de grãos em arroz. Goiás, 1999.

ELIAS, M. C. F.; OLIVEIRA, M.; VANIER, N.L. (Ed.). Qualidade de arroz da póscolheita ao consumo. Pelotas: Ed. Universidade da UFPEL, 2012. cap. 13, p. 193212.VANIER, N.L. (Ed.). Qualidade de arroz da pós-colheita ao consumo. Pelotas: Ed. Universidade da UFPEL, 2012.

FERREIRA, C. M.; YOKOYAMA, L. P. Cadeia produtiva do arroz na Região CentroOeste. Brasília: Embrapa Produção de Informações, 110 p, 1999.

FLANDRIN, J. L.; MONTANARI, M. (Dir.). História da alimentação. São Paulo: Estação Liberdade, 1998.

FONSECA, H. Os fungos e a deterioração de alimentos. Disponível: <http: //www.micotoxinas.com.br/boletim4.htm>. Acesso em 11 de jun. 2019.

GUIMARÃES ICO, PEREIRA J, CORNÉLIO VMO, BATISTA LR, EVANGELISTA RM, Ferreira EB. Comparação de metodologias para detecção de fungos em arroz irradiado. Rev Inst Adolfo Lutz. São Paulo, 2010; 69 (2):194-200. JULIANO, B. O. Rice in human nutrition. Rome. FAO, 1993. Disponível em: <http://www. fao.org/docrep/t0567e/T0567E00.htm\#Contents>. Acesso em: 2 ago. 2019.

HOELTZ, M.; FAGUNDES, C. A.; ALCAYAGA, E. A. L.; NOLL, I. B. Micobiota e micotoxinas em amostras de arroz coletadas durante o sistema estacionário de secagem e armazenamento. Ciência Rural, v.39, p. 803-808, 2009.

HUNT, J. R.; JOHNSON, L. K.; JULIANO, B. O. Bioavailability of zinc from cooked Philippine milled, undermilled, and brown rice, as assessed in rats by using growth, bone zinc and zinc retention. Journal of Agriculture and Food Chemistry, v. 50, n. 18, p. 5229-5235, 2002. 
JULIANO, B. O. Rice in human nutrition. Rome. FAO, 1993. Disponível em: <http://www.fao.org/docrep/t0567e/T0567E00.htm\#Contents>. Acesso em: 05 mai. 2019.

KIESSLING, K. H. Biochemical mecanismo faction of micotocins. Pure \& Applied Chemistry. v.58, n.2, p. 327-338, 1986.

KJER, J.; DEBBAB, A.; ALY, A. H.; PROKSCH, P. Methods for isolation of marinederivedendo phytic fungi and thei rbioactive secondary products. Nature Protocols. London, v. 5, n. 3, p. 479-490, 2010. PMid: 20203665. <http://dx.doi.org/10.1038/ nprot.2009.233>. Acesso em: 2 ago 2019.

LOBO, da S. V. L.; DE FILIPPI, CORSI M. C., M, RESENDE M.; E SILVA, F. R. Qualidade microbiológica do arroz comercializado em Goiânia, Goiás. Santo Antônio de Goiás: Embrapa Arroz e Feijão, 2010. 20 p. - (Documentos / Embrapa Arroz e Feijão, ISSN 1678-9644 ; 261).

LORINI, I.; MIIKE, L. H.; SCUSSEL, V. M.; Armazenagem de grãos. Campinas: Instituto BioGeneziz, 983 p. 2002.

LUZ, M.L.G.S., TREPTOW, R.O. Avaliação de preferência-consumo de arroz parboilizado e branco polido. Bol. SBCTA, 28 (2):106-112, 1994.

MALLMANN CA, SANTURIO JM, WENTZ I. Aflatoxinas - Aspectos clínicos e toxicológicos em suínos. Ciência Rural, Santa Maria. 24 (3): 635-43. 1994.

MARIA A. C., RITA F. R., MARIANA S., JOÃO Q., MARIA C. P., MARIA A. Mucormicose Rino-Cerebral: Caso Clínico e Revisão de Literatura. Revista da Sociedade Portuguesa de Oftalmologia. Serviço de Oftalmologia, Centro Hospitalar do Porto.Vol. 35 - № 4 -Dezembro 2011.

MATTOS, M. T. L; MARTINS, J. da S. F. Cultivo de arroz irrigado orgânico no Rio Grande do Sul. Pelotas: Embrapa Clima Temperado, 2009. 161 p.:il.; $21 \mathrm{~cm}$. (Sistemas de produção/Embrapa Clima Temperado). 
MCLEAN, J.; DAWE, D.; HARDY, B.; HETTEL, G. Rice almanac: source book for the most important economic activity on earth. Los Baños: IRRI, 2002. p. 298.

OSBORNE, B. G. Micotoxins and the Cereal Industry. A Revie. Journal of Food Technologyn, v.17, p. 1-9, 1982.

PACHECO, F. Sequenciamento, identificação e análise de genes de arroz envolvidos na interação com Herbaspirillum seropedicae. 2008. 68 f. Dissertação (Mestre em Bioquímica) - Universidade Federal do Paraná, Curitiba, 2008.

PARK , K.Y.; BULLERMAN, L.B. Effect of cycling temperatures on aflatoxin production by Aspergillus parasiticus and Aspergillus flavus in rice and cheddar cheese. Journal of Food Science, Chicago, v.48, p.889-896, 1983.

PEREIRA, J. A. Cultura do arroz no Brasil: subsídios para a sua história. Teresina: Embrapa Meio-Norte, 2002.

PERSON, A. K., CHUDGAR, S. M., NORTON, B. L., TONG, B. C. e STOUT, J. E. Aspergillus niger: an unusual cause of invasive pulmonary aspergillosis, Journal of Medical Microbiology. 59, pp. 834-838, 2010.

PITT, J. I. , HOCKING, A. D. Fungiand Food Spoilage. New York: Springer Science Business Media, 2009.

PITT, J. I. ; HOCKING, A. D. Fungiand Food Spoilage. Blackie Academic \& Professional, 1997, 529p.

PITT, J. I.; TANIWAKI, M. H.; COLE, M. B. Mycotoxin production in major crops as influenced by growing, harvesting, storage and processing, with emphasis on the achievement of food safety objectives. Food Control, Guildford, v. 32, n. 1, p. 205-215, 2013. http://dx.doi.org/10.1016/j.foodcont.2019.09.027. Acesso em: 5 mai 2019.

PUZZI, D. Abastecimento e Armazenagem de grãos. Campinas: Instituto Campineiro de Ensino Agrícola, 666 p, 2000. 
ROVARIS, M. L. et al. Fungos e micotoxinas em arroz armazenado. In: SIMPÓSIO SUL-BRASILEIRO DE QUALIDADE DO ARROZ, 2003, Pelotas. Anais. Pelotas, 109126p, 2003.

SAFRAS \& MERCADO. Publicação quinzenal sobre tendências de mercado. ARROZ. Porto Alegre, jan. 1998.

SCHELL. W.A., Histopathology of fungal rhinosinusitis, Otolaryngol. Clin Northam. 33 251-279, 2000.

TRABULSI, L. R. et. al. Biologia dos fungos. In: GOMPERTZ, O. F. et al. Microbiologia médica. São Paulo: Atheneu, p. 365-374, 1999.

USDA/FAS. Grain: world markets and trade. May, 2015. Disponível em: <https://apps.fas. usda.gov/psdonline/circulars/grain.pdf>. Acesso em: 09 jun. 2019.

VIEIRA, N. R. A.; RABELO, R. R. Qualidade tecnológica. In: SANTOS, A. B.; STONE, L. F.; VIEIRA, N. R. A. A cultura do arroz no Brasil. 2. ed. Santo Antônio da Goiás: Embrapa Arroz e Feijão, cap. 23. p. 869-900, 2006.

WALTER, M.; MARCHEZAN, E.; AVILA, L. A. Arroz: composição e características nutricionais. Ciência Rural. Santa Maria, v. 38, n. 4, p. 1184-1192, 2008.

ZLOTOWSKI P, CORRÊA AMR, ROZZA DB, DRIEMEIER D, MALLMANN CA, MIGLIAVACCA FA. Surto e aflatoxicose em suínos no Estado do Rio Grande do Sul, Pesq. Vet. Bras. out./dez. 2004; 24 (4): 207-10.

Enviado: Março, 2020.

Aprovado: Março, 2020. 